\title{
Variability of the Martian ionosphere from the MAVEN Radio Occultation Science Experiment
}

\author{
MeiJuan Yao', Jun Cui 1,2,3*, XiaoShu Wu'2,3, YingYing Huang', and WenRui Wang' \\ ${ }^{1}$ School of Atmospheric Sciences, Sun Yat-sen University, Zhuhai Guangdong 519082, China; \\ ${ }^{2}$ National Astronomical Observatories of China, Chinese Academy of Sciences, Beijing 100101, China; \\ ${ }^{3}$ Chinese Academy of Sciences Center for Excellence in Comparative Planetology, Hefei 230026, China
}

\begin{abstract}
The Martian ionosphere is produced by a number of controlling processes, including solar extreme ultraviolet radiation (EUV) and X-ray ionization, impact ionization by precipitating electrons, and day-to-night transport. This study investigates the structural variability of the Martian ionosphere with the aid of the radio occultation (RO) experiments made on board the recent Mars Atmosphere and Volatile Evolution (MAVEN) spacecraft. On the dayside, the RO electron density profiles are described by the superposition of two Chapman models, representing the contributions from both the primary layer and the low-altitude secondary layer. The inferred subsolar peak electron densities and altitudes are $1.24 \times 10^{5} \mathrm{~cm}^{-3}$ and $127 \mathrm{~km}$ for the former, and $4.28 \times 10^{4} \mathrm{~cm}^{-3}$ and $97 \mathrm{~km}$ for the latter, respectively, in general agreement with previous results appropriate for the low solar activity conditions. Our results strengthen the role of solar EUV and X-ray ionization as the driving source of plasma on the dayside of Mars. Beyond the terminator, a systematic decline in ionospheric total electron content is revealed by the MAVEN RO measurements made from the terminator crossing up to a solar zenith angle of $120^{\circ}$. Such a trend is indicative of day-to-night plasma transport as an important source for the nightside Martian ionosphere.
\end{abstract}

Keywords: Mars; planetary ionospheres; radio occultation

Citation: Yao, M. J., Cui, J., Wu, X. S., Huang, Y. Y., and Wang, W. R. (2019). Variability of the Martian ionosphere from the MAVEN Radio Occultation Science Experiment. Earth Planet. Phys., 3(4), 283-289. http://doi.org/10.26464/epp2019029

\section{Introduction}

The dayside Martian ionosphere contains a well-defined primary layer (hereafter denoted as $\mathrm{M}_{2}$ ) and a low-altitude secondary layer (hereafter denoted as $M_{1}$ ), which are frequently depicted as analogous to the terrestrial $\mathrm{F}$ and $\mathrm{E}$ layers (Mendillo et al., 2003; Rishbeth and Mendillo, 2004). These layers are mainly produced by solar extreme ultraviolet radiation (EUV) and X-ray ionization along with impact ionization by photoelectrons and their secondaries (Withers, 2009 and references therein). Their structures are reasonably well described by the idealized Chapman theory, varying systematically with both the solar zenith angle (SZA) and the solar ionizing flux (e.g., Hantsch and Bauer, 1990; Martinis et al., 2003; Withers and Mendillo, 2005; Fox and Yeager, 2006, 2009; Nielsen et al., 2006; Morgan et al., 2008; Fox and Weber, 2012).

On the nightside, the Martian ionosphere is patchy and sporadic, with electron precipitation generally thought to be the dominant source of ionization (e.g., Verigin et al., 1991; Safaeinili et al., 2007; Fowler et al., 2015; Girazian et al., 2017a). In practice, energetic electrons capable of ionizing the nightside Martian atmosphere could be either solar wind electrons or photoelectrons produced on the dayside and transported to the nightside under favorable ambient magnetic field configurations (Xu SS et al., 2016, 2017;

Correspondence to: J. Cui, cuijun7@mail.sysu.edu.cn

Received 25 MAR 2019; Accepted 17 APR 2019.

Accepted article online 09 MAY 2019.

C 2019 by Earth and Planetary Physics.
Weber et al., 2017; Adams et al., 2018). In addition, horizontal transport has been suggested as a viable mechanism supporting a nightside ionosphere on Mars, especially near the terminator (e.g., Zhang et al., 1990; Němec et al., 2010; Duru et al., 2011; Withers et al., 2012a; Cui J et al., 2015a; Girazian et al., 2017b).

A significant amount of information on the structural variability of the Martian ionosphere comes from a large collection of vertical electron density profiles acquired by the Radio Occultation (RO) Science Experiments (e.g., Withers, 2009 and references therein). Such experiments have been made on board the Mariner 9, Mars Orbiter, Vikings 1 and 2, Mars Global Surveyor (MGS), and Mars Express (MEx), among others (e.g., Kliore et al., 1972, 1973; Lindal et al., 1979; Tyler et al., 1992, 2001; Hinson et al., 1999; Pätzold et al., $2005,2016)$. With such a technique, the radio links between the orbiters and the ground-based telescopes on Earth are used to measure the signal variations caused by changes in the local refractivity of the Martian ionosphere (e.g., Withers et al., 2014). Radio occultation experiments were also made on board the recent Mars Atmosphere and Volatile Evolution (MAVEN; Jakosky et al., 2015). With the release of the MAVEN RO electron density profiles, it is an opportune time to investigate the variability of the Martian ionosphere further with these new data sets and compare them with early results.

\section{Data Description}

The MAVEN RO Science Experiment is a two-way, single-fre- 
quency (at X-band) RO experiment that provides information on the vertical electron density profiles in the Martian ionosphere. The analysis presented here relies exclusively on the MAVEN RO measurements made from 5 Jul 2016 to 13 Oct 2018, a period under solar minimum conditions and covering the entire surface of Mars over an SZA range of $54^{\circ}-131^{\circ}$. Information on the solar EUV and X-ray irradiance is available from the MAVEN Extreme Ultraviolet Monitor (EUVM) measurements (Eparvier et al., 2015); thus, extrapolation from the near-Earth measurements, as required by previous analyses of the Mars aeronomical data (Withers, 2009 and references therein), is no longer necessary. Here, with the aid of the EUVM Level 3 solar spectral model at Mars constructed from the Flare Irradiance Spectral Model for Mars and calibrated with the EUVM band irradiance data (Thiemann et al., 2017), we estimate the integrated solar energy flux shortward of $89.8 \mathrm{~nm}$, corresponding to the energy range above the nominal $\mathrm{CO}_{2}$ ionization potential of $13.8 \mathrm{eV}$ (Bhardwaj and Jain, 2009), as 0.75-1.5 $\mathrm{erg} \cdot \mathrm{cm}^{-2} \cdot \mathrm{s}^{-1}$

For reference, in Figure 1 we provide the distributions of the available RO measurements with respect to longitude and latitude in the left panel and with respect to the SZA and solar ionizing flux in the right panel. All geophysical parameters in the figure refer to the values at the closest approach of the downlink ray. Because the majority of the available RO measurements were made at an SZA below $120^{\circ}$ (with only eight individual profiles in the range of $\left.120^{\circ}-135^{\circ}\right)$, here we restrict our analysis of the ionospheric variability on Mars to the dayside and the cross-terminator regions only. For reference, the MGS RO measurements cover an SZA range of $70^{\circ}-90^{\circ}$, whereas the MEx RO measurements cover an SZA range of $50^{\circ}-120^{\circ}$, in comparison with the maximum possible SZA range of $44^{\circ}-136^{\circ}$ potentially sampled by the RO technique (Gurnett et al., 2008).

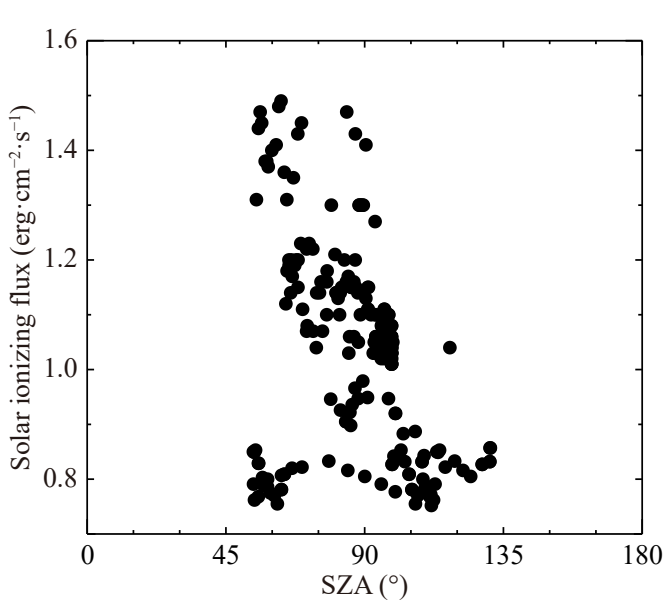

Figure 1. Distributions of the available MAVEN RO measurements from 5 Jul 2016 to 13 Oct 2018 with respect to longitude and latitude in the left panel, and with respect to the SZA and solar ionizing flux in the right panel. All geophysical parameters refer to the values at the closest approach of the downlink ray. The solar ionizing flux is obtained by integrating the MAVEN Extreme Ultraviolet Monitor (EUVM) solar spectral model shortward of $89.8 \mathrm{~nm}$. Each point in the figure represents an individual electron density profile.

\section{Variability of the Martian lonosphere}

\subsection{The Dayside Martian Ionosphere}

Several representative electron density profiles on the dayside of Mars are displayed in Figure 2 in order of increasing SZA from left to right. All manifest as a regular morphology with a pronounced primary layer lying on top of a secondary layer, with the latter typically appearing as a mere shoulder (e.g. Withers, 2009). The MAVEN RO measurements reveal dayside variability in terms of the presence or absence of a clearly identified ionopause (Vogt et al., 2015), the flatness or sharpness of the primary peak (Withers et al., 2012b), and the emergence of transient layers (Kopf et al., 2008), among others. Overlying such variability is the ordered trend of decreasing peak electron density and increasing peak electron altitude, both with an increasing SZA.

To investigate the variations in the primary and secondary layers, we used the sum of two idealized Chapman functions to model the measured electron density profile, where each Chapman function characterizes the contribution of an individual layer, either $M_{2}$ or $M_{1}$. Kopf et al. (2008) used a similar approach based on the sum of several Gaussian functions to describe the superposition of multiple layer structures present in the dayside Martian ionosphere. Our approach involves six independent free parameters, including the peak electron densities and altitudes, as well as the respective neutral-density scale heights for both layers, which are constrained by data-model comparison with the aid of the traditional Levenberg-Marquardt least-squares fitting algorithm. The appropriate functional form can be written as

$$
N_{\mathrm{e}}=\sum_{i=1}^{2} N_{i \mathrm{~m}} \exp \left\{\frac{1}{2}\left[1-\frac{z-z_{i \mathrm{~m}}}{H_{i}}-\exp \left(-\frac{z-z_{i \mathrm{~m}}}{H_{i}}\right)\right]\right\},
$$

where $N_{\mathrm{e}}$ is the electron number density, and $N_{i m}, z_{i m}$, and $H_{i}$ are the peak electron density, peak electron altitude, and appropriate neutral density scale height, respectively, for layer $i$ ( 2 for the primary layer and 1 for the secondary layer following the conventional nomenclature). The data-model comparison is restricted to regions typically extending above the primary peak for several tens of kilometers because the electron distribution at higher alti- 

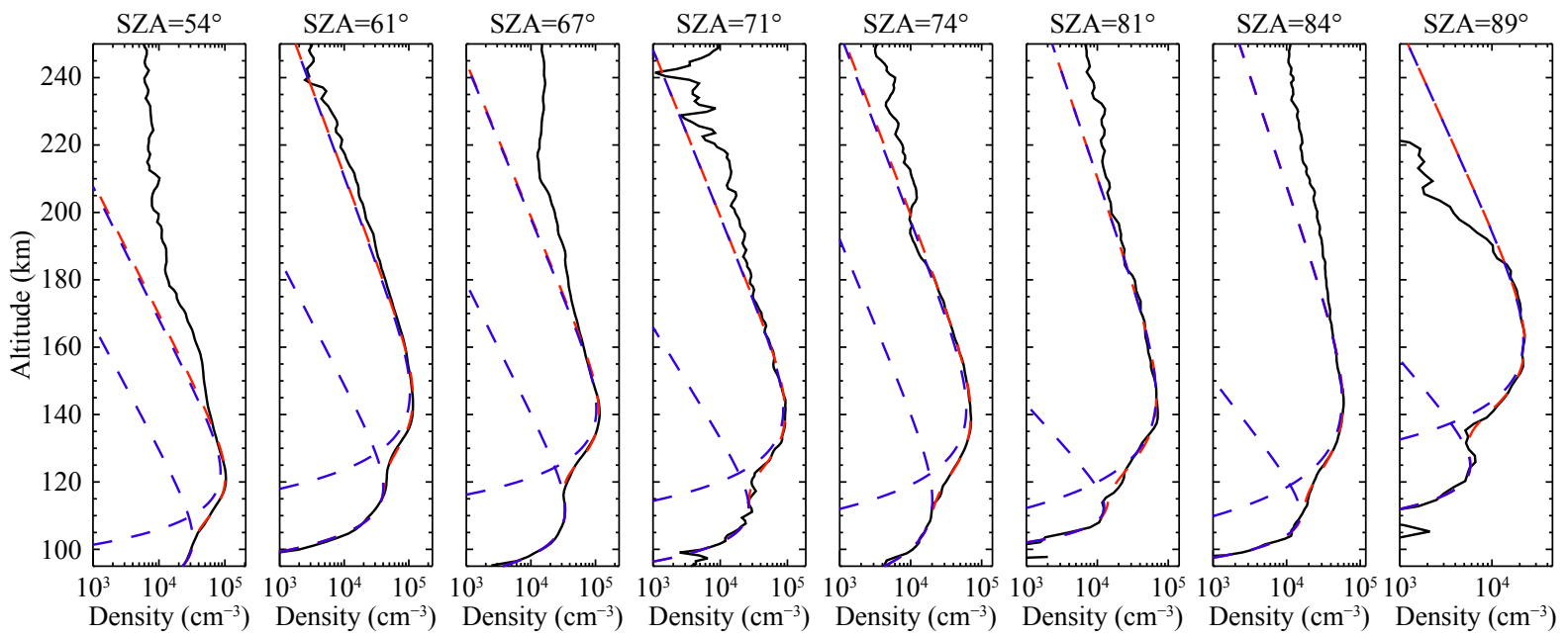

Figure 2. Representative electron density profiles of the dayside Martian ionosphere based on the MAVEN RO measurements (solid black lines), along with the double Chapman model fits (dashed red lines), in order of increasing SZA from left to right. The respective contributions of the $M_{2}$ and $M_{1}$ layers are indicated by dashed blue lines for reference.

tudes is known to be dynamically controlled rather than photochemically controlled, either under diffusive equilibrium (e.g., Martinis et al., 2003; Fox and Yeager, 2006; Matta et al., 2015) or subject to bulk ion outflow (e.g., Fox, 1997, 2009; Wu WS et al., 2019). Note that the condition of photochemical equilibrium is an underlying assumption of the idealized Chapman theory (Chapman, 1931a, b ). Under some circumstances, a portion of the measured electron density profile well below the secondary peak is also excluded from the data-model comparison because of the potential presence of a meteoric layer (e.g., Pätzold et al., 2005; Withers et al., 2008; Schneider et al., 2015). In practice, the altitude range used for the double Chapman model fitting is determined manually for each individual electron density profile examined here. The upper boundary is typically placed at $180 \mathrm{~km}$ above the surface, where we could estimate a chemical loss time constant of $600 \mathrm{~s}$ via dissociative recombination (e.g., Peverall et al., 2001), assuming a reference electron density of $10^{4} \mathrm{~cm}^{-3}$ (see Figure 2) and reference electron temperature of $500 \mathrm{~K}$ (Ergun et al., 2015; Cui J et al., 2015b). For comparison, the plasma diffusion time constant is comparable, with a reference ion-neutral colli- sion frequency of $1 \mathrm{~s}^{-1}$ (Schunk, 1977), a reference background neutral density of $10^{9} \mathrm{~cm}^{-3}$, and a reference neutral density scale height of $10 \mathrm{~km}$ (Mahaffy et al., 2015). For the profiles displayed in Figure 2, the best-fit model results are superimposed on the red solid lines for comparison, and the respective contributions of the two layers are indicated by the dashed blue lines.

The SZA variations of the best-fit peak electron densities and altitudes are displayed in Figure 3, with red indicating $M_{2}$ and blue indicating $M_{1}$, respectively, in agreement with the prediction of the solar-driven scenario. The variations for the $M_{2}$ layer can be reasonably described by

$$
\begin{aligned}
N_{2 \mathrm{~m}} & =1.24 \times 10^{5}(\cos \theta)^{0.39} \mathrm{~cm}^{-3}, \\
z_{2 \mathrm{~m}} & =127-9.3 \times \ln (\cos \theta) \mathrm{km},
\end{aligned}
$$

where $\theta$ is the SZA. Equations (2a) and (2b) predict a subsolar peak electron density of $1.24 \times 10^{5} \mathrm{~cm}^{-3}$ at $127 \mathrm{~km}$. In comparison, Hantsch and Bauer (1990) found the subsolar $\mathrm{M}_{2}$ peak to be $2 \times 10^{5}$ $\mathrm{cm}^{-3}$ at $120 \mathrm{~km}$ based on pre-MGS RO measurements, Fox and Yeager (2009) and Fox and Weber (2012) found it to be 1.5x
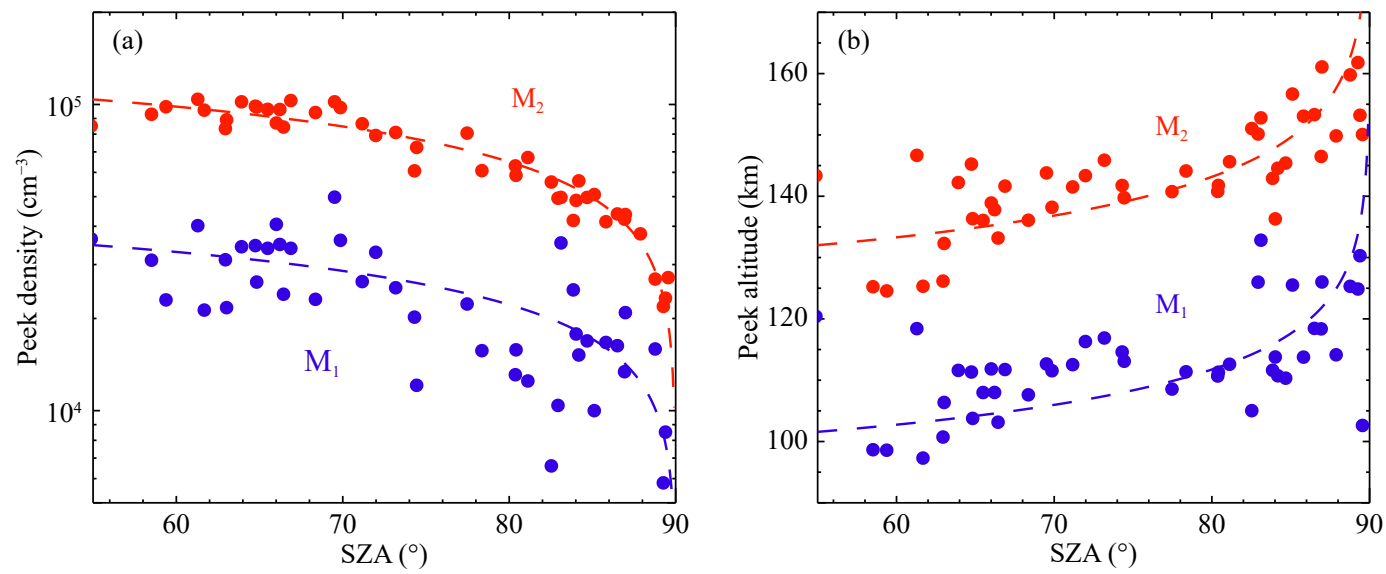

Figure 3. SZA variations of the best-fit peak electron densities (a) and peak electron altitudes (b) based on the available MAVEN RO measurements. Red indicates the $\mathrm{M}_{2}$ layer, and blue indicates the $\mathrm{M}_{1}$ layer, respectively. 
$10^{5} \mathrm{~cm}^{-3}$ at $126 \mathrm{~km}$ based on MGS RO measurements, Zhang SJ et al. (2015) found it to be $1.5 \times 10^{5} \mathrm{~cm}^{-3}$ at $128 \mathrm{~km}$ based on MEx RO measurements, and Morgan et al. (2008) found it to be $1.6 \times$ $10^{5} \mathrm{~cm}^{-3}$ at $134 \mathrm{~km}$ based on MEx MARSIS measurements in the active ionospheric sounding mode.

The largest discrepancy was encountered when comparing our result with an early investigation by Hantsch and Bauer (1990), whose $\mathrm{M}_{2}$ peak electron density at subsolar conditions was higher than our value by $60 \%$. Such a discrepancy is not surprising, given that the analysis of Hantsch and Bauer (1990) was made with pre-MGS RO data accumulated over a wide range, with a $10.7 \mathrm{~cm}$ solar radio index of 70 to 200 solar flux units (SFU, 10-22 $\mathrm{W} \cdot \mathrm{m}^{-2} \cdot \mathrm{Hz}^{-1}$ ), whereas the available MAVEN RO data were gathered exclusively under low solar activity conditions with a mean 10.7 $\mathrm{cm}$ solar radio index of $75 \mathrm{SFU}$. Because the MEx RO and MARSIS data were also acquired under low solar activity conditions, the subsolar peak electron density for $\mathrm{M}_{2}$ in the present study is in general agreement with the earlier analyses of Zhang SJ et al. (2015) and Morgan et al. (2008). In addition, we should emphasize that the MGS RO measurements were made over a wide range, with a $10.7 \mathrm{~cm}$ solar radio index of 80 to 200 SFU. However, the subsolar peak electron density for $\mathrm{M}_{2}$ quoted above has been corrected for the solar cycle variation and is appropriate for a MAVEN equivalent mean $10.7 \mathrm{~cm}$ solar radio index of $75 \mathrm{SFU}$. Regarding the subsolar peak electron altitude for $\mathrm{M}_{2}$, our results were in general agreement with various studies and the typical difference was only several kilometers. This result indicates that the solar ionizing flux influences the peak electron density more prominently than the peak electron altitude. For a direct comparison with our result, the MGS subsolar peak electron altitude of $126 \mathrm{~km}$ found by Fox and Weber (2012) represents the value averaged over different longitudinal bins and weighted by the respective numbers of available RO electron density profiles in these bins. A systematic longitudinal pattern, manifesting as a strong wave- 3 feature, is well known to be present on Mars and is thought to be linked to the nonmigrating tidal waves in the ambient neutral atmosphere (e.g., Bougher et al., 2001, 2004), but such a feature cannot be confirmed by the longitudinally averaged analysis presented here and is left for follow-up studies.

Similarly, the SZA variations for the $M_{1}$ layer under solar minimum conditions, as inferred from the MAVEN RO measurements, can be described by

$$
\begin{aligned}
N_{1 \mathrm{~m}} & =4.28 \times 10^{4}(\cos \theta)^{0.38} \mathrm{~cm}^{-3}, \\
z_{1 \mathrm{~m}} & =97-8.5 \times \ln (\cos \theta) \mathrm{km},
\end{aligned}
$$

predicting a subsolar peak electron density of $4.28 \times 10^{4} \mathrm{~cm}^{-3}$ at 97 km. By comparison, Fox and Yeager (2009) and Fox and Weber (2012) found such a peak to be located at a longitudinally averaged altitude of $108 \mathrm{~km}$ with a peak density of $5.5 \times 10^{4} \mathrm{~cm}^{-3}$ appropriate for a mean $10.7 \mathrm{~cm}$ solar radio index of $75 \mathrm{SFU}$. Although the subsolar peak electron densities for $M_{1}$ from the two works are in reasonable agreement, the relatively large discrepancy in the subsolar peak electron altitude (by $11 \mathrm{~km}$ ) is likely indicative of the difficulty of separating the contribution of the weak and noisy $M_{1}$ layer from the total electron density profile.
Except close to the terminator, the SZA variations of the peak electron densities for both layers vary ideally with $(\cos \theta)^{0.5}$ according to the Chapman theory (e.g., Morgan et al., 2008), but in practice, the two power indexes are usually found to be substantially different from 0.5 because of the inherent approximations in the Chapman theory (Chapman, 1931a, b ). Here, the power indexes were estimated to be nearly 0.4 for both layers based on the MAVEN RO data and are broadly consistent with the 0.45 for $M_{2}$ and 0.39 for $M_{1}$ reported by Fox and Yeager (2009) based on MGS RO measurements.

Finally, we note that the dayside averaged neutral density scale heights implied by equations (2) and (3) were $9.3 \mathrm{~km}$ and $8.5 \mathrm{~km}$, respectively, around the $M_{2}$ and $M_{1}$ peaks. These values were different from previous estimates by $\pm 30 \%$ : $10 \mathrm{~km}$ reported by Hantsch and Bauer (1990) based on pre-MGS RO measurements, $6.8 \mathrm{~km}$ for $M_{2}$ and $4.2 \mathrm{~km}$ for $M_{1}$ by Fox and Weber (2012) based on MGS RO measurements, and $12.9 \mathrm{~km}$ by Morgan et al. (2008) based on MEX MARSIS measurements, where the MGS values were again obtained by averaging over different longitudinal bins. Provided that the scale height obtained from Chapman fitting is a useful diagnostic for the ambient neutral temperature, we would expect the pre-MGS and MGS values, which characterize both low and high solar activity conditions, to be higher than the MEx and MAVEN values, which characterize exclusively low solar activity conditions (e.g., Jain et al., 2015; Bougher et al., 2017), but this is clearly not the case. As discussed by Cui J et al. (2015b), the scale height from Chapman fitting does not necessarily represent the true neutral density scale height because of the nonnegligible contribution of a positive electron temperature gradient, in comparison with the constant electron temperature assumed in the Chapman theory (Chapman, 1931a, b ). In practice, a steep electron temperature gradient is present near the ionospheric peak on Mars according to both numerical calculations (e.g., Chen RH et al., 1978; Choi et al., 1998; Matta et al., 2014) and spacecraft in situ measurements (e.g., Hanson and Mantas, 1988; Ergun et al., 2015; Flynn et al., 2017).

\subsection{The Cross-terminator Martian Ionosphere}

Approximately half of the available MAVEN RO electron density profiles are located within the SZA range of $90^{\circ}-120^{\circ}$, providing a sufficiently large sample for investigating the morphological variability of the cross-terminator Martian ionosphere. Several representative profiles are presented in Figure 4 in order of increasing SZA from left to right. The figure reveals a considerably larger variability as compared with the dayside, which strengthens the earlier conclusion that the Martian ionosphere beyond the terminator is patchy and sporadic (e.g., Gurnett et al., 2008). Yet unlike the dayside, not all profiles present distinctive layer structures; accordingly, we did not attempt Chapman fits to the electron density profiles beyond the terminator. Instead, the variation in the cross-terminator Martian ionosphere was investigated in terms of the total electron content (TEC) obtained by the column integrating the measured electron density profiles.

The SZA variation of the ionospheric TEC beyond the terminator is displayed in Figure 5 over an SZA range of $90^{\circ}-120^{\circ}$. At the terminator crossing, the TEC derived from the RO density profiles 

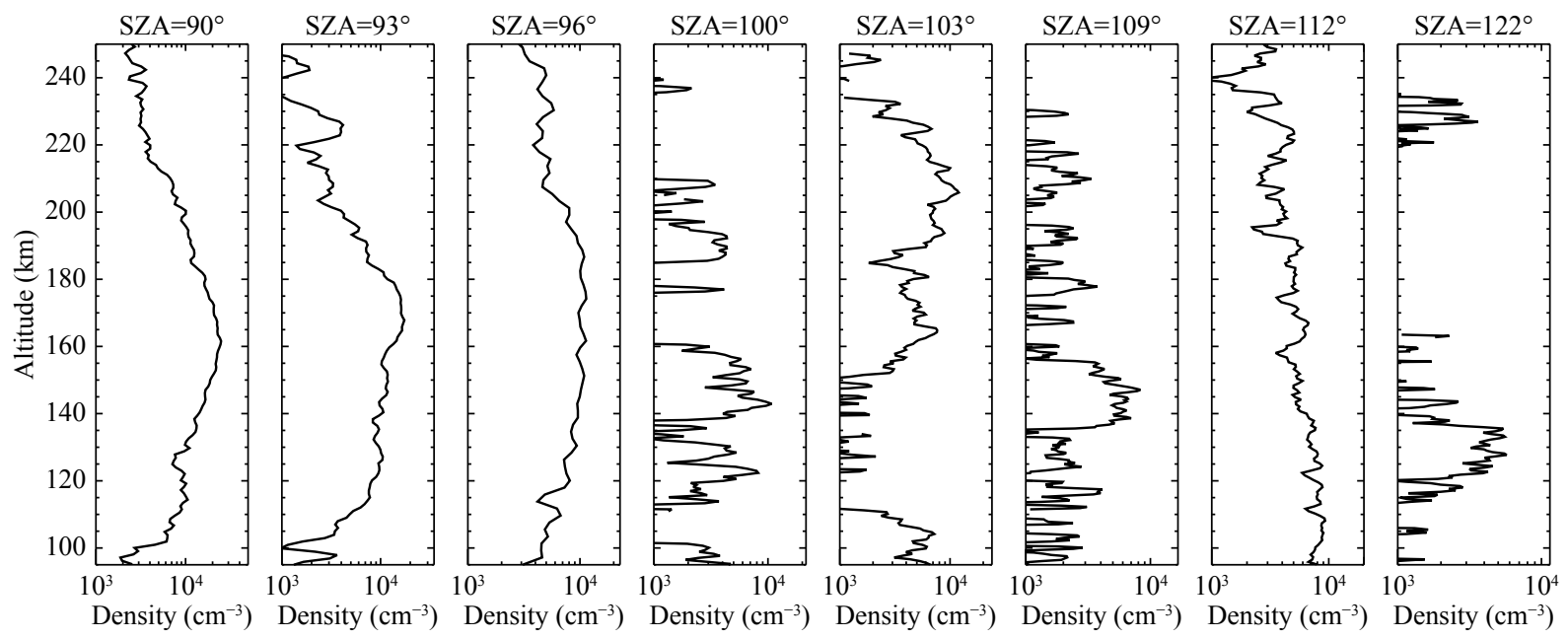

Figure 4. Representative electron density profiles of the cross-terminator Martian ionosphere based on MAVEN RO measurements, in order of increasing SZA from left to right.

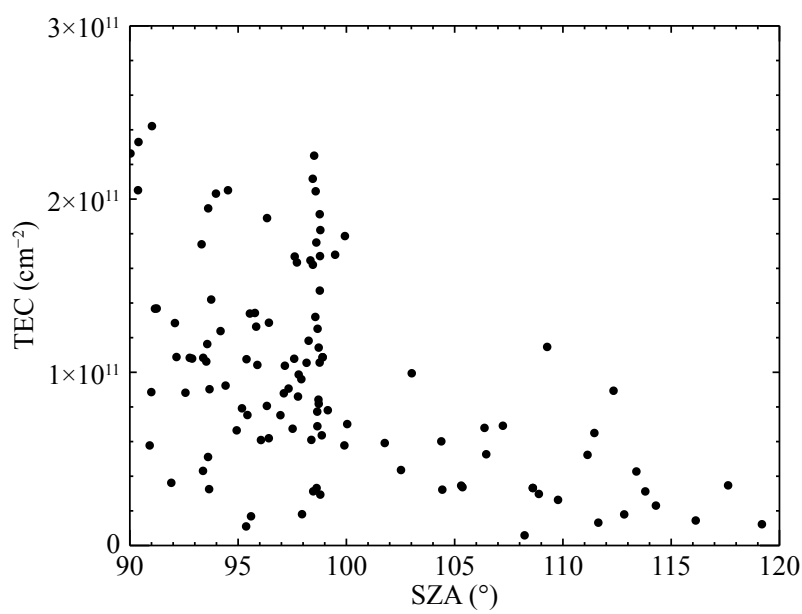

Figure 5. SZA variation of the ionospheric TEC on Mars over an SZA range of $90^{\circ}-120^{\circ}$.

typically lies over a range of $(1-2) \times 10^{11} \mathrm{~cm}^{-2}$, consistent with MARSIS subsurface measurements (e.g., Cui J et al., 2015a). Despite the considerable scattering as compared with the dayside SZA variation (see Figure 3), the nightside RO data suggest the appearance of a general trend, with the TEC decreasing systematically beyond the terminator crossing. Such behavior is consistent with previous results obtained from the pre-MGS RO data (Zhang SJ et al., 2015), the MEx RO data (Withers et al., 2012a), and the MEX MARSIS data in both the active ionospheric sounding mode (Němec et al., 2010; Duru et al., 2011) and the subsurface mode (Cui J et al., 2015a). This trend should reflect the combined effect of solar EUV and X-ray ionization, which does not decline to become nonnegligible beyond the terminator because of the finite thickness of the Martian atmosphere, and day-to-night transport, which manifests as a continuous depletion of the ionospheric plasma content by dissociative recombination as Mars rotates into the darkness. At an even larger SZA, we would expect the ionospheric TEC on Mars to remain at a roughly constant level in response to solar wind electron precipitation as the dominant source of ionization and to be independent of the SZA (Withers et al., 2012; Cui J et al., 2015a). However, only eight individual RO electron density profiles are available at an SZA $>120^{\circ}$, which does not allow for rigorous evaluation of the role of electron precipitation.

\section{Concluding Remarks}

The $\mathrm{RO}$ experiments provide useful information on the electron density profiles throughout the Martian ionosphere by using radio links between the orbiters and the ground-based telescopes to measure the signal variations caused by changes in the local refractivity of the ionosphere (e.g., Withers et al., 2014). Like the previous RO experiments conducted on board the Mariner 9, Mars Orbiter, Vikings 1 and 2, MGS, and MEx, the MAVEN RO measurements provide a useful data set for examining the ionospheric variability on Mars. In this study, we analyzed the available MAVEN RO electron density profiles, which covered an SZA range of up to $120^{\circ}$. On the dayside, we modeled the measured electron density profiles with the superposition of two Chapman functions to include the contributions of both the primary $\mathrm{M}_{2}$ layer and the lowaltitude $\mathrm{M}_{1}$ layer (Mendillo et al., 2003; Rishbeth and Mendillo, 2004). On the nightside, we parameterized the measured electron density profiles by using the respective TEC values.

Our analysis generally confirms the solar-driven scenario for the dayside Martian ionosphere. The SZA variations in the peak electron densities and peak electron altitudes for both layers are in agreement with predictions by the idealized Chapman theory (Chapman, 1931a, b ). The inferred subsolar peak electron densities are $1.24 \times 10^{5} \mathrm{~cm}^{-3}$ at $127 \mathrm{~km}$ for $\mathrm{M}_{2}$ and $4.28 \times 10^{4} \mathrm{~cm}^{-3}$ at 97 $\mathrm{km}$ for $M_{1}$, appropriate for low solar activity conditions with a mean $10.7 \mathrm{~cm}$ solar radio index of $75 \mathrm{SFU}$. These values are consistent with previous values found from different data sets and under similar solar activity conditions (e.g., Morgan et al., 2008; Fox and Yeager, 2009; Fox and Weber, 2012; Zhang SJ et al., 2015). The dominant role of solar wind electron precipitation on the deep nightside of Mars (e.g., Verigin et al., 1991; Safaeinili et al., 2007; Fowler et al., 2015; Girazian et al., 2017a) will need to be examined further as more $\mathrm{RO}$ electron density profiles are accumulated at an SZA $>120^{\circ}$. 


\section{Acknowledgments}

J Cui acknowledges support from the National Natural Science Foundation of China (NSFC) through grant numbers 41525015 and 41774186 . The data used in this study are publicly available at the MAVEN Science Data Center (https://lasp.colorado.edu/maven/ sdc/public/Flight/) and the NASA Planetary Data System (https:// pds-ppi.igpp.ucla.edu/Flight/).

\section{References}

Adams, D., Xu, S., Mitchell, D. L., Lillis, R. J., Fillingim, M., Andersson, L., Fowler, C., Connerney, J. E. P., Espley, J., and Mazelle, C. (2018). Using magnetic topology to probe the sources of Mars' nightside ionosphere. Geophys. Res. Lett., 45(22), 12190-12197. https://doi.org/10.1029/2018GL080629

Bhardwaj, A., and Jain, S. K. (2009). Monte Carlo model of electron energy degradation in a $\mathrm{CO}_{2}$ atmosphere. J. Geophys. Res. Space Phys., 114(A11), A11309. https://doi.org/10.1029/2009JA014298

Bougher, S. W., Engel, S., Hinson, D. P., and Forbes, J. M. (2001). Mars Global Surveyor radio science electron density profiles: Neutral atmosphere implications. Geophys. Res. Lett., 28(16), 3091-3094. https://doi.org/10.1029/2001GL012884

Bougher, S. W., Engel, S., Hinson, D. P., and Murphy, J. R. (2004). MGS radio science electron density profiles: Interannual variability and implications for the Martian neutral atmosphere. J. Geophys. Res. Planets, 109(E3), E03010. https://doi.org/10.1029/2003JE002154

Bougher, S. W., Roeten, K. J., Olsen, K., Mahaffy, P. R., Benna, M., Elrod, M., Jain, S. K., Schneider, N. M., Deighan, J., ... Jakosky, B. M. (2017). The structure and variability of Mars dayside thermosphere from MAVEN NGIMS and IUVS measurements: Seasonal and solar activity trends in scale heights and temperatures. J. Geophys. Res. Space Phys., 122(1), 1296-1313. https://doi.org/10.1002/2016JA023454

Chapman, S. (1931a). The absorption and dissociative or ionizing effect of monochromatic radiation in an atmosphere on a rotating Earth. Proc. Phys. Soc., 43(1), 26. https://doi.org/10.1088/0959-5309/43/1/305

Chapman, S. (1931b). The absorption and dissociative or ionizing effect of monochromatic radiation in an atmosphere on a rotating Earth Part II. Grazing incidence. Proc. Phys. Soc., 43(5), 483-501. https://doi.org/10.1088/0959-5309/43/5/302

Chen, R. H., Cravens, T. E., and Nagy, A. F. (1978). The Martian ionosphere in light of the Viking observations. J. Geophys. Res., 83(A8), 3871-3876. https://doi.org/10.1029/JA083iA08p03871

Choi, Y. W., Kim, J., Min, K. W., Nagy, A. F., and Oyama, K. I. (1998). Effect of the magnetic field on the energetics of Mars ionosphere. Geophys. Res. Lett., 25(14), 2753-2756. https://doi.org/10.1029/98GL51839

Cui, J., Galand, M., Yelle, R. V., Wei, Y., and Zhang, S. J. (2015a). Day-to-night transport in the Martian ionosphere: Implications from total electron content measurements. J. Geophys. Res. Space Phys., 120(3), 2333-2346. https://doi.org/10.1002/2014JA020788

Cui, J., Galand, M., Zhang, S. J., Vigren, E., and Zou, H. (2015b). The electron thermal structure in the dayside Martian ionosphere implied by the MGS radio occultation data. J. Geophys. Res. Planets, 120(2), 278-286. https://doi.org/10.1002/2014JE004726

Duru, F., Gurnett, D. A., Morgan, D. D., Winningham, J. D., Frahm, R. A., and Nagy, A. F. (2011). Nightside ionosphere of Mars studied with local electron densities: A general overview and electron density depressions. J. Geophys. Res. Space Phys., 116(A10), A10316. https://doi.org/10.1029/2011JA016835

Eparvier, F. G., Chamberlin, P. C., Woods, T. N., and Thiemann, E. M. B. (2015). The solar extreme ultraviolet monitor for MAVEN. Space Sci. Rev., 195(1-4), 293-301. https://doi.org/10.1007/s11214-015-0195-2

Ergun, R. E., Morooka, M. W., Andersson, L. A., Fowler, C. M., Delory, G. T., Andrews, D. J., Eriksson, A. I., McEnulty, T., and Jakosky, B. M. (2015). Dayside electron temperature and density profiles at Mars: First results from the MAVEN Langmuir probe and waves instrument. Geophys. Res. Lett., 42(21), 8846-8853. https://doi.org/10.1002/2015GL065280

Flynn, C. L., Vogt, M. F., Withers, P., Andersson, L., England, S., and Liu, G. P. (2017). MAVEN observations of the effects of crustal magnetic fields on electron density and temperature in the Martian dayside ionosphere. Geophys. Res. Lett., 44(21), 10812-10821. https://doi.org/10.1002/2017GL075367

Fowler, C. M., Andersson, L., Ergun, R. E., Morooka, M., Delory, G., Andrews, D. J., Lillis, R. J., McEnulty, T., Weber, T. D., ... Jakosky, B. M. (2015). The first in situ electron temperature and density measurements of the Martian nightside ionosphere. Geophys. Res. Lett., 42(21), 8854-8861.

https://doi.org/10.1002/2015GL065267

Fox, J. L. (1997). Upper limits to the outflow of ions at Mars: Implications for atmospheric evolution. Geophys. Res. Lett., 24(22), 2901-2904. https://doi.org/10.1029/97GL52842

Fox, J. L., and Yeager, K. E. (2006). Morphology of the near-terminator Martian ionosphere: A comparison of models and data. J. Geophys. Res. Space Phys., 111(A10), A10309. https://doi.org/10.1029/2006JA011697

Fox, J. L. (2009). Morphology of the dayside ionosphere of Mars: Implications for ion outflows. J. Geophys. Res. Planets, 114(E12), E12005. https://doi.org/10.1029/2009JE003432

Fox, J. L., and Yeager, K. E. (2009). MGS electron density profiles: Analysis of the peak magnitudes. Icarus, 200(2), 468-479. https://doi.org/10.1016/j.icarus.2008.12.002

Fox, J. L., and Weber, A. J. (2012). MGS electron density profiles: Analysis and modeling of peak altitudes. Icarus, 221(2), 1002-1019. https://doi.org/10.1016/j.icarus.2012.10.002

Girazian, Z., Mahaffy, P., Lillis, R. J., Benna, M., Elrod, M., Fowler, C. M., and Mitchell, D. L. (2017a). Ion densities in the nightside ionosphere of Mars: Effects of electron impact ionization. Geophys. Res. Lett., 44(22), 11248-11256. https://doi.org/10.1002/2017GL075431

Girazian, Z., Mahaffy, P. R., Lillis, R. J., Benna, M., Elrod, M., and Jakosky, B. M. (2017b). Nightside ionosphere of Mars: Composition, vertical structure, and variability. J. Geophys. Res. Space Phys., 122(4), 4712-4725. https://doi.org/10.1002/2016JA023508

Gurnett, D. A., Huff, R. L., Morgan, D. D., Persoon, A. M., Averkamp, T. F., Kirchner, D. L., Duru, F., Akalin, F., Kopf, A. J., ... Picardi, G. (2008). An overview of radar soundings of the Martian ionosphere from the Mars Express spacecraft. Adv. Space Res., 41(9), 1335-1346. https://doi.org/10.1016/j.asr.2007.01.062

Hanson, W. B., and Mantas, G. P. (1988). Viking electron temperature measurements: Evidence for a magnetic field in the Martian ionosphere. J. Geophys. Res. Space Phys., 93(A7), 7538-7544. https://doi.org/10.1029/JA093iA07p07538

Hantsch, M. H., and Bauer, S. J. (1990). Solar control of the Mars ionosphere. Planet. Space Sci., 38(4), 539-542. https://doi.org/10.1016/00320633(90)90146-H

Hinson, D. P., Simpson, R. A., Twicken, J. D., Tyler, G. L., and Flasar, F. M. (1999). Initial results from radio occultation measurements with Mars Global Surveyor. J. Geophys. Res. Planets, 104(E11), 2699727012. https://doi.org/10.1029/1999JE001069

Jain, S. K., Stewart, A. I. F., Schneider, N. M., Deighan, J., Stiepen, A., Evans, J. S., Stevens, M. H., Chaffin, M. S., Crismani, M., ... Jakosky, B. M. (2015). The structure and variability of Mars upper atmosphere as seen in MAVEN/IUVS dayglow observations. Geophys. Res. Lett., 42(21), 9023-9030. https://doi.org/10.1002/2015GL065419

Jakosky, B. M., Grebowsky, J. M., Luhmann, J. G., and Brain, D. A. (2015). Initial results from the MAVEN mission to Mars. Geophys. Res. Lett., 42(21), 8791-8802. https://doi.org/10.1002/2015GL065271

Kliore, A. J., Cain, D. L., Fjeldbo, G., Seidel, B. L., Sykes, M. J., and Rasool, S. I. (1972). The atmosphere of Mars from Mariner 9 radio occultation measurements. Icarus, 17(2), 484-516. https://doi.org/10.1016/00191035(72)90014-0

Kliore, A. J., Fjeldbo, G., Seidel, B. L., Sykes, M. J., and Woiceshyn, P. M. (1973). S band radio occultation measurements of the atmosphere and topography of Mars with Mariner 9: Extended mission coverage of polar and intermediate latitudes. J. Geophys. Res., 78(20), 4331-4351. https://doi.org/10.1029/JB078i020p04331

Kopf, A. J., Gurnett, D. A., Morgan, D. D., and Kirchner, D. L. (2008). Transient layers in the topside ionosphere of Mars. Geophys. Res. Lett., 35(17), L17102. https://doi.org/10.1029/2008GL034948

Lindal, G. F., Hotz, H. B., Sweetnam, D. N., Shippony, Z., Brenkle, J. P., Hartsell, G. 
V., Spear, R. T., and Michael, Jr. W. H. (1979). Viking radio occultation measurements of the atmosphere and topography of Mars: Data acquired during 1 Martian year of tracking. J. Geophys. Res. Solid Earth, 84(B14), 8443-8456. https://doi.org/10.1029/JB084iB14p08443

Mahaffy, P. R., Benna, M., Elrod, M., Yelle, R. V., Bougher, S. W., Stone, S. W., and Jakosky, B. M. (2015). Structure and composition of the neutral upper atmosphere of Mars from the MAVEN NGIMS investigation. Geophys. Res. Lett., 42(21), 8951-8957. https://doi.org/10.1002/2015GL065329

Martinis, C. R., Wilson, J. K., and Mendillo, M. J. (2003). Modeling day-to-day ionospheric variability on Mars. J. Geophys. Res. Space Phys., 108(A10), 1383. https://doi.org/10.1029/2003JA009973

Matta, M., Galand, M., Moore, L., Mendillo, M., and Withers, P. (2014). Numerical simulations of ion and electron temperatures in the ionosphere of Mars: Multiple ions and diurnal variations. Icarus, 227, 78-88. https://doi.org/10.1016/j.icarus.2013.09.006

Matta, M., Mendillo, M., Withers, P., and Morgan, D. (2015). Interpreting Mars ionospheric anomalies over crustal magnetic field regions using a 2-D ionospheric model. J. Geophys. Res. Space Phys., 120(1), 766-777. https://doi.org/10.1002/2014JA020721

Mendillo, M., Smith, S., Wroten, J., Rishbeth, H., and Hinson, D. (2003). Simultaneous ionospheric variability on Earth and Mars. J. Geophys. Res., 108(A12), 1432. https://doi.org/10.1029/2003JA009961

Morgan, D. D., Gurnett, D. A., Kirchner, D. L., Fox, J. L., Nielsen, E., and Plaut, J. J. (2008). Variation of the Martian ionospheric electron density from Mars Express radar soundings. J. Geophys. Res., 113(A9), A09303. https://doi.org/10.1029/2008JA013313

Němec, F., Morgan, D. D., Gurnett, D. A., and Duru, F. (2010). Nightside ionosphere of Mars: Radar soundings by the Mars Express spacecraft. J. Geophys. Res., 115(E12), E12009. https://doi.org/10.1029/2010JE003663

Nielsen, E., Zou, H., Gurnett, D. A., Kirchner, D. L., Morgan, D. D., Huff, R., Orosei, R., Safaeinili, A., Plaut, J. J., and Picardi, G. (2006). Observations of vertical reflections from the topside Martian lonosphere. Space Sci. Rev., 126(1-4), 373-388. https://doi.org/10.1007/s11214-006-9113-y

Pätzold, M., Tellmann, S., Häusler, B., Hinson, D., Schaa, R., and Tyler, G. L. (2005). A sporadic third layer in the ionosphere of Mars. Science, 310(5749), 837-839. https://doi.org/10.1126/science. 1117755

Pätzold, M., Häusler, B., Tyler, G. L., Andert, T., Asmar, S. W., Bird, M. K., Dehant, V., Hinson, D. P., Rosenblatt, P., ... Remus, S. (2016). Mars express 10 years at mars: observations by the Mars express radio science experiment (MaRS). Planet. Space Sci., 127, 44-90. https://doi.org/10.1016/j.pss.2016.02.013

Peverall, R., Rosén, S., Peterson, J. R., Larsson, M., Al-Khalili, A., Vikor, L., Semaniak, J., Bobbenkamp, R., Le Padellec, A., ... van der Zande, W. J. (2001). Dissociative recombination and excitation of $\mathrm{O}_{2}^{+}$: Cross sections, product yields and implications for studies of ionospheric airglows. J. Chem. Phys., 114(15), 6679-6689. https://doi.org/10.1063/1.1349079

Rishbeth, H., and Mendillo, M. (2004). lonospheric layers of Mars and Earth. Planet. Space Sci., 52(9), 849-852. https://doi.org/10.1016/j.pss.2004.02.007

Safaeinili, A., Kofman, W., Mouginot, J., Gim, Y., Herique, A., Ivanov, A. B., Plaut, J. J., and Picardi, G. (2007). Estimation of the total electron content of the Martian ionosphere using radar sounder surface echoes. Geophys. Res. Lett., 34(23), L23204. https://doi.org/10.1029/2007GL032154

Schneider, N. M., Deighan, J. I., Stewart, A. I. F., McClintock, W. E., Jain, S. K., Chaffin, M. S., Stiepen, A., Crismani, M., Plane, J. M. C., ... Jakosky, B. M. (2015). MAVEN IUVS observations of the aftermath of the Comet Siding Spring meteor shower on Mars. Geophys. Res. Lett., 42(12), 4755-4761. https://doi.org/10.1002/2015GL063863

Schunk, R. W. (1977). Mathematical structure of transport equations for multispecies flows. Rev. Geophys. Space Phys., 15(4), 429-445. https://doi.org/10.1029/RG015i004p00429

Thiemann, E. M. B., Chamberlin, P. C., Eparvier, F. G., Templeman, B., Woods, T. N., Bougher, S. W., and Jakosky, B. M. (2017). The MAVEN EUVM model of solar spectral irradiance variability at Mars: Algorithms and results. J. Geophys. Res. Space Phys., 122(3), 2748-2767. https://doi.org/10.1002/2016JA023512

Tyler, G. L., Balmino, G., Hinson, D. P., Sjogren, W. L., Smith, D. E., Woo, R., Asmar, S. W., Connally, M. J., Hamilton, C. L., and Simpson, R. A. (1992). Radio science investigations with Mars Observer. J. Geophys. Res., 97(E5),
7759-7779. https://doi.org/10.1029/92JE00513

Tyler, G. L., Balmino, G., Hinson, D. P., Sjogren, W. L., Smith, D. E., Simpson, R. A., Asmar, S. W., Priest, P., and Twicken, J. D. (2001). Radio science observations with Mars Global Surveyor: Orbit insertion through one Mars year in mapping orbit. J. Geophys. Res. Planets, 106(E10), 23327-23348. https://doi.org/10.1029/2000JE001348

Verigin, M. I., Gringauz, K. I., Shutte, N. M., Haider, S. A., Szego, K., Kiraly, P., Nagy, A. F., and Gombosi, T. I. (1991). On the possible source of the ionization in the nighttime Martian ionosphere: 1. Phobos 2 Harp electron spectrometer measurements. J. Geophys. Res. Space Phys., 96(A11), 19307-19313. https://doi.org/10.1029/91JA00924

Vogt, M. F., Withers, P., Mahaffy, P. R., Benna, M., Elrod, M. K., Halekas, J. S., Connerney, J. E. P., Espley, J. R., Mitchell, D. L., ... Jakosky, B. M. (2015). lonopause-like density gradients in the Martian ionosphere: A first look with MAVEN. Geophys. Res. Lett., 42(21), 8885-8893. https://doi.org/10.1002/2015GL065269

Weber, T., Brain, D., Mitchell, D., Xu, S. S., Connerney, J., and Halekas, J. (2017). Characterization of low-altitude nightside Martian magnetic topology using electron pitch angle distributions. J. Geophys. Res. Space Phys., 122(10), 9777-9789. https://doi.org/10.1002/2017JA024491

Withers, P., and Mendillo, M. (2005). Response of peak electron densities in the Martian ionosphere to day-to-day changes in solar flux due to solar rotation. Planet. Space Sci., 53(14-15), 1401-1418. https://doi.org/10.1016/j.pss.2005.07.010

Withers, P., Mendillo, M., Hinson, D. P., and Cahoy, K. (2008). Physical characteristics and occurrence rates of meteoric plasma layers detected in the Martian ionosphere by the Mars Global Surveyor Radio Science Experiment. J. Geophys. Res. Space Phys., 113(A12), A12314. https://doi.org/10.1029/2008JA013636

Withers, P. (2009). A review of observed variability in the dayside ionosphere of Mars. Adv. Space Res., 44(3), 277-307. https://doi.org/10.1016/j.asr.2009.04.027

Withers, P., Fillingim, M. O., Lillis, R. J., Häusler, B., Hinson, D. P., Tyler, G. L., Pätzold, M., Peter, K., Tellmann, S., and Witasse, O. (2012a). Observations of the nightside ionosphere of Mars by the Mars Express Radio Science Experiment (MaRS). J. Geophys. Res. Space Phys., 117(A12), A12307. https://doi.org/10.1029/2012JA018185

Withers, P., Fallows, K., Girazian, Z., Matta, M., Häusler, B., Hinson, D., Tyler, L., Morgan, D., Pätzold, M., ... Witasse, O. (2012b). A clear view of the multifaceted dayside ionosphere of Mars. Geophys. Res. Lett., 39(18), L18202. https://doi.org/10.1029/2012GL053193

Withers, P., Moore, L., Cahoy, K., and Beerer, I. (2014). How to process radio occultation data: 1 . From time series of frequency residuals to vertical profiles of atmospheric and ionospheric properties. Planet. Space Sci., 101, 77-88. https://doi.org/10.1016/j.pss.2014.06.011

Wu, X. S., Cui, J., Xu, S. S., Lillis, R. J., Yelle, R. V., Edberg, N. J. T., Vigren, E., Rong, Z. J., Fan, K., ... Mitchell, D. L. (2019). The morphology of the topside Martian ionosphere: Implications on bulk ion flow. J. Geophys. Res., 124(3), 734-751. https://doi.org/10.1029/2018JE005895

Xu, S. S., Mitchell, D., Liemohn, M., Dong, C. F., Bougher, S., Fillingim, F., Lillis, R., McFadden, J., Mazelle, C., ... Jakosky, M. (2016). Deep nightside photoelectron observations by MAVEN SWEA: Implications for Martian northern hemispheric magnetic topology and nightside ionosphere source. Geophys. Res. Lett., 43(17), 8876-8884. https://doi.org/10.1002/2016GL070527

Xu, S. S., Mitchell, D., Liemohn, M., Fang, X. H., Ma, Y. J., Luhmann, J., Brain, D., Steckiewicz, M., Mazelle, C., ... Jakosky, B. (2017). Martian low-altitude magnetic topology deduced from MAVEN/SWEA observations. J. Geophys. Res. Space Phys., 122(2), 1831-1852. https://doi.org/10.1002/2016JA023467

Zhang, M. H. G., Luhmann, J. G., and Kliore, A. J. (1990). An observational study of the nightside ionospheres of Mars and Venus with radio occultation methods. J. Geophys. Res. Space Phys., 95(A10), 17095-17102. https://doi.org/10.1029/JA095iA10p17095

Zhang, S. J., Cui, J., Guo, P., Li, J. L., Ping, J. S., Jian, N. C., and Zhang K. F. (2015). Martian electron density profiles retrieved from Mars Express dualfrequency radio occultation measurements. Adv. Space Res., 55(9), 2177-2189. https://doi.org/10.1016/j.asr.2015.01.030 